\title{
Abnormal ventricular repolarisation in association with myocardial bridging
}

\author{
John W Dean, Peter G Mills
}

\begin{abstract}
Myocardial bridging causing systolic compression of epicardial coronary arteries may be an incidental finding at coronary arteriography. Bridging rarely causes myocardial ischaemia. A young man presented with chest pain and striking abnormalities of ventricular repolarisation that initially were treated as myocardial infarction. At cardiac catheterisation the coronary arteries were normal apart from the presence of a myocardial bridge affecting a major diagonal branch of the left anterior descending artery. Echocardiography was normal with no features of hypertrophic cardiomyopathy.
\end{abstract}

(Br Heart F 1994;71:366-367)

\section{Case report}

A 25 year old carpenter presented to his local hospital with atypical chest pain lasting for one hour which had developed while he was driving and was associated with nausea, vomiting, and dizziness. The electrocardiogram showed sinus rhythm with a normal axis and with deep $\mathrm{T}$ wave inversion in leads $\mathrm{I}, \mathrm{aVL}$, and V2-V6 (fig 1). Myocardial infarction was suspected and he was treated with streptokinase. Subsequent electrocardiograms were unchanged and cardiac enzymes were not raised. The chest $x$ ray was normal. In an exercise tolerance test performed before discharge the patient exercised for 9.5 minutes of the standard Bruce protocol without symptoms. The peak heart rate was 146 beats $/ \mathrm{min}$ and the blood pressure response was normal. There were no significant ST segment changes with exercise but there was "pseudonormalisation" of the inverted $\mathrm{T}$ waves. $\mathrm{He}$ was discharged to be followed up as an outpatient.

Two weeks later he was readmitted with similar symptoms which had persisted for eight hours, and an ECG that was identical with the one recorded during the earlier episode of chest pain. Because of his recurring, undiagnosed, chest pain he was referred for coronary arteriography.

At cardiac catheterisation left ventricular end diastolic pressure was $12 \mathrm{~mm} \mathrm{Hg}$, with no outflow tract gradient. Both coronary arteries appeared angiographically normal apart from a muscular bridge that caused compression of a large diagonal branch of the left anterior descending artery during systole (fig 2). Left ventricular cineangiography was normal.

$\mathrm{He}$ was examined by transoesophageal echocardiography because the transthoracic images were not good. The left ventricle was normal with no features to suggest hypertrophic cardiomyopathy.

\section{Discussion}

Although intramyocardial segments of the major epicardial coronary arteries were seen in $20 \%$ of hearts examined at necropsy, ${ }^{1}$ myocardial bridging was seen in only $0.5 \%$ of patients undergoing coronary arteriography and was almost exclusively confined to the territory of the left anterior descending artery. ${ }^{2}$ Most commonly the mid or distal segment of the left anterior descending (LAD) coronary artery follows an intramyocardial course and is compressed during systole. It is of normal calibre during diastole. Because most myocardial blood flow occurs in diastole myocardial bridging is usually regarded as a benign, incidental finding. However, ischaemia may result when bridging is pronounced or when tachycardia occurs. ${ }^{3}$
Cardiac Department, Royal London Hospital, London

JW Dean

P G Mills

Correspondence to: Dr J W Dean, Cardiac Department, Royal London Hospital, London E1 1BB.

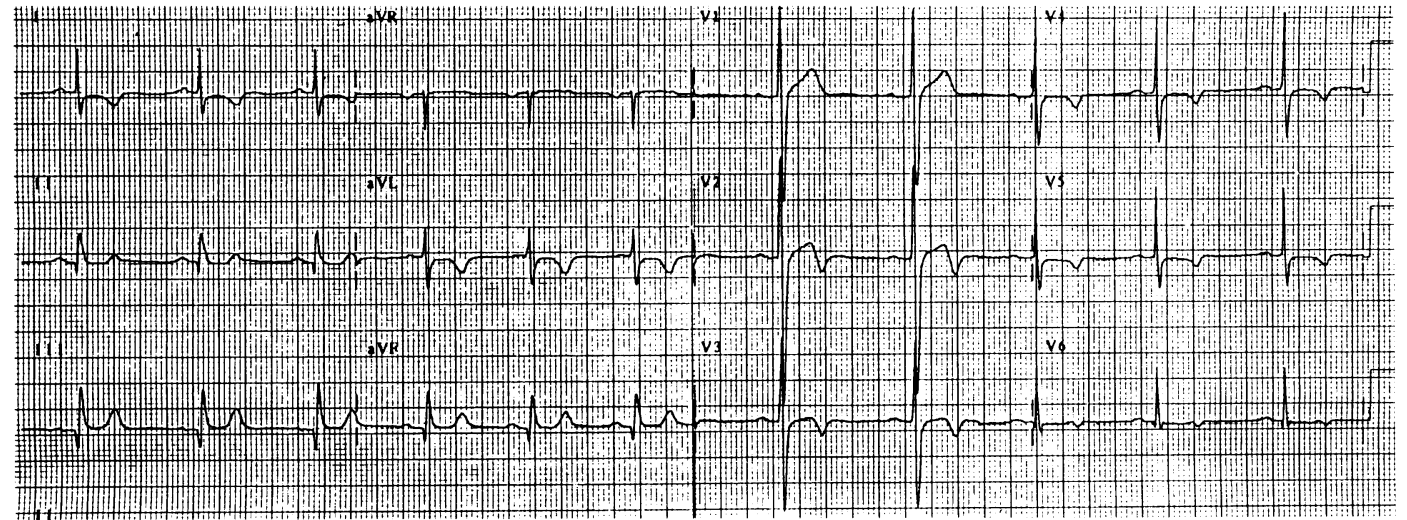

Figure 1 Resting 12 lead electrocardiogram. 


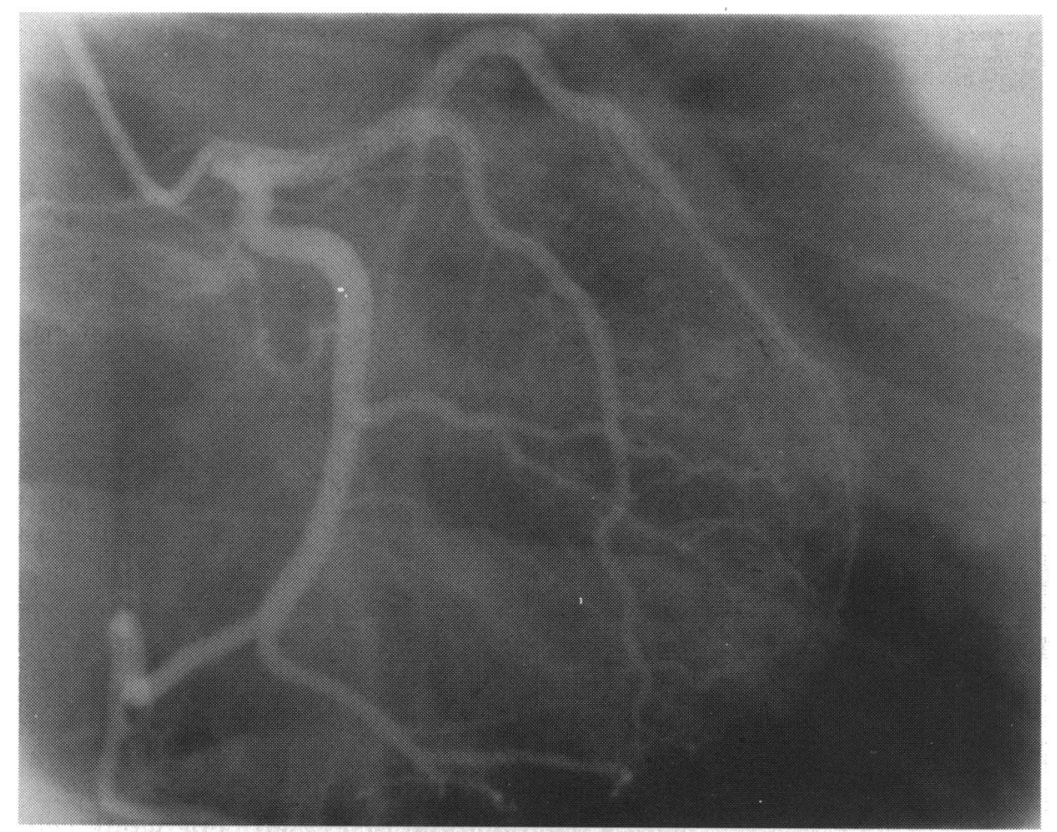

In this patient the diagonal branch of the LAD coronary artery was bridged and there was also slight systolic compression of the main artery. The electrocardiographic abnormalities are unlikely to be caused by bridging alone, particularly because the exercise electrocardiograph was normal. A myocardial abnormality is the most likely explanation, although echocardiography excluded hypertrophic cardiomyopathy.

1 Geiringer E. The mural coronary artery. Am Heart f 1951; 41:359-68.

2 Kramer JR, Kitazume H, Proudfit WL, Sones FM Jr. Clinical significance of isolated coronary bridges. Benign and frequent condition affecting the left anterior descending artery. Am Heart $₹$ 1982;103:283-8.

3 Faruqui AMA, Maloy WC, Felner JM, Schlant RC, Logan WD, Symbas P. Symptomatic myocardial bridging of coronary artery. Am $\mathcal{F}$ Cardiol 1978;41:1305-10.

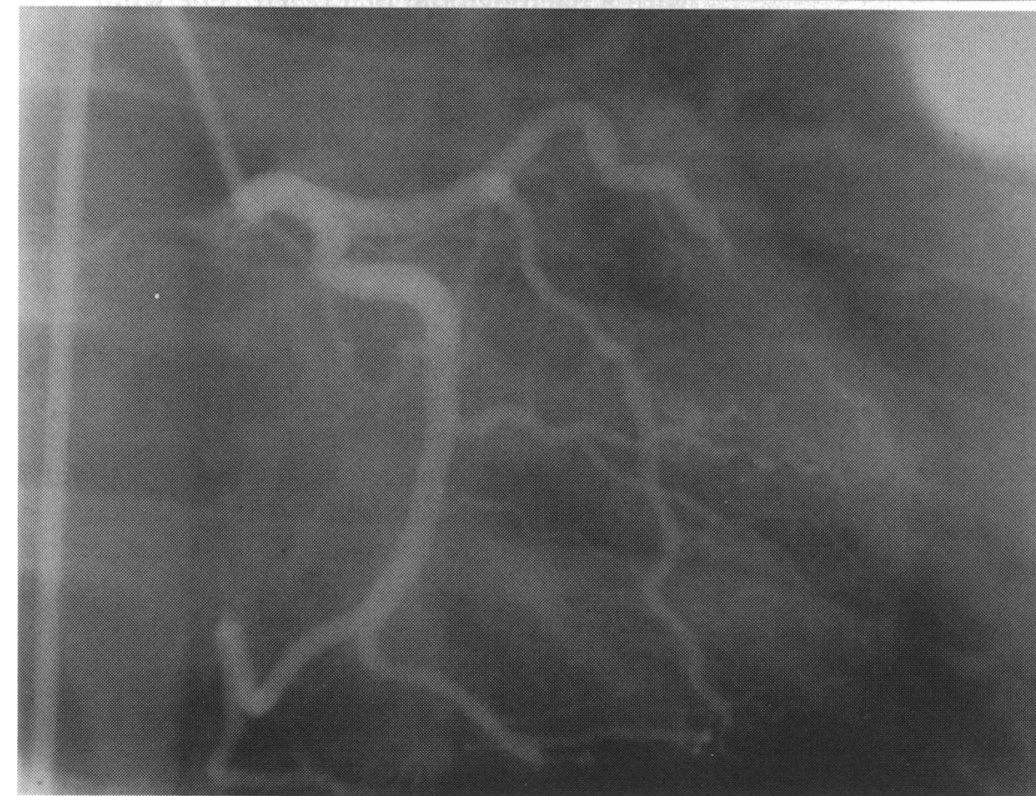

Figure 2 Left coronary arteriogram in the right anterior oblique projection in diastole (upper panel) and in systole (lower panel). During systole the diagonal branch of the left anterior descending coronary artery was compressed, as was the main left anterior descending artery itself but to a lesser extent. 